\title{
REVALIDAÇÃO DO GÊNERO DEMOPHOO (COLEOPTERA, CERAMBYCIDAE, LAMIINAE)
}

\author{
Carlos Eduardo de Alvarenga Julio ${ }^{1,2}$
}

\begin{abstract}
REVALIDATION OF THE GENUS DEMOPHOO (COLEOPTERA, CERAMBYCIDAE, LAMIINAE). Demophoo Thomson, 1864 is removed from the synonymy of Hoplistocerus Blanchard, 1847. The genus and D. hammatus (Chabrillac, 1857) are redescribed.
\end{abstract}

KEYWORDS. Cerambycidae, Anisocerini, Demophoo, taxonomy, Neotropical.

\section{INTRODUÇÃO}

O gênero Demophoo foi proposto por THOMson (1864) para Onychocerus hammatus Chabrillac, 1857. LACORDAIRE (1872) redescreveu o gênero e comentou que este "est trèsdistinct et ne contient qu' une petite espèce du Brésil, remarquable par sa livrée uniforme d' un blanc grisâtre et tiquetée de petits points noirs; les antennes sont annelées de la même couleur; les points des élytres sont dus à des granulations dénudées". BATES (1875) sinonimizou Demophoo com Hoplistocerus Blanchard, 1847, afirmando que "the genus Demophoo Thomson, admitted by Lacordaire, cannot be separated from Hoplistocerus. D. hammatus, which I have had an opportunity of studying in the rich collection of Dr. Baden, somewhat resembles H. gemmatus (Bates), Nicaragua, but is perfectly distinct species, with an obtuse lateral tubercle to the prothorax". GounELLE (1906), ao revisar o gênero Hoplistocerus, separou, na chave para espécies, H. hammatus de todas as demais espécies, com base em caracteres do escapo, tórax e élitros.

É proposta a revalidação do gênero Demophoo com base em caracteres das antenas e élitros e no aspecto geral da superfície corporal. Foram examinados espécimens pertencentes às coleções do Museu Nacional, Universidade Federal do Rio de Janeiro (MNRJ) e Museu de Zoologia, Universidade de São Paulo (MZSP).

\section{Demophoo Thomson, 1864, revalidado}

Demophoo Thomson, 1864:21, 352; LACORDAIRE, 1872:725.

Espécie-tipo: Onychocerus hammatus Chabrillac, 1857 (designação original).

1. Departamento de Entomologia, Museu Nacional,Universidade Federal do Rio Janeiro, Quinta da Boa Vista, São Cristóvão, 20940-040, Rio de Janeiro, RJ, Brasil. (ceajulio@ig.com.br)

2. Doutorando em Ciências Biológicas, Instituto de Biociências, UNESP, Botucatu, SP. 
Superfície corporal revestida por densa pubescência decumbente. Cabeça granulada na fronte e com pontos profundos no vértex. Fronte um pouco convexa, com os lados ligeiramente convergentes para a região inferior; margem inferior e a sutura epistomal retas. Olhos pequenos, divididos, apenas um fino friso separando os lobos superior e inferior, os superiores tão distantes entre si quanto, aproximadamente, três vezes a largura de um lobo; tubérculos anteníferos afastados entre si e um pouco projetados. Antenas, longas, ultrapassam os ápices elitrais, tanto nos machos como nas fêmeas; escapo robusto, clavado; lado interno do ápice do pedicelo e do antenômero III com espinho longo e afilado, do antenômero IV com um espinho curto e rombo e do V ligeiramente intumescido; antenômeros III e IV subiguais em comprimento e um pouco mais longos que o escapo; V-X gradualmente decrescentes em comprimento; o XI mais longo que o precedente e com a forma de aguilhão recurvado.

Protórax com pequeno tubérculo lateral pouco proeminente; pronoto com pequenas elevações laterais no disco e pontuado nas margens anterior e posterior; processo prosternal estreito e o mesosternal alargado posteriormente, sem tubérculos. Élitros densamente granulados, com duas pequenas elevações manifestas, uma centro-basal e outra no terço apical, planos nos $2 / 3$ basais, em declive no terço apical, aplanados nos lados do disco e ligeiramente estreitados no meio; úmeros salientes e ápices subarredondados. Fêmures pedunculados, os anteriores mais robustos nos machos; tíbias gradualmente alargadas para os ápices, as protíbias com escavação interna no terço apical, mais acentuada nos machos; protarsos alargados e lateralmente franjados nos machos. Urosternito $\mathrm{V}$ das fêmeas com o comprimento dos três anteriores reunidos e ligeiramente intumescido no ápice.

Comentários. Distingue-se de Hoplistocerus, proposto por Blanchard (1847), pela superfície corporal revestida por densa pubescência decumbente; pela fronte granulada; pelos lobos oculares superiores tão distantes entre si quanto, aproximadamente, três vezes a largura de um lobo; pelo escapo clavado; pelo aspecto do protórax, com um pequeno tubérculo lateral pouco proeminente e o pronoto com pequenas elevações laterais, pontuado nas margens anterior e posterior e pelo aspecto dos élitros, densamente granulados, com duas pequenas elevações manifestas, uma centro-basal e outra no terço apical, planos nos $2 / 3$ basais, em declive no terço apical, aplanados nos lados do disco e ligeiramente estreitados no meio, com os úmeros salientes e os ápices subarredondados. Em Hoplistocerus: superfície corporal glabra; fronte densa e finamente pontuada, sem grânulos; lobos oculares superiores tão distantes entre si quanto a largura de um lobo; escapo piriforme; protórax sem tubérculos e pronoto estriado transversalmente; élitros planos, densamente pontuados, sem grânulos e paralelos nos 2/3 basais, com os úmeros não salientes e os ápices arredondados.

\section{Demophoo hammatus (Chabrillac, 1857)}

(Fig.1)

Onychocerus hammatus Chabrillac, 1857:199.

Demophoo hamatus; Thomson, 1864:21; LACORDAIRE, 1872:726.

Hoplistocerus hamatus; Gounelle, 1906:10; LANE, 1938:108, est.3, figs. b, c; ZiKÁn \& ZiKán, 1944:33 (distr.); ZaJciw, 1958:17 (distr.); 1972:67 (distr.).

Hoplistocerus hammatus; MonNÉ, 1994:12 (cat.). 


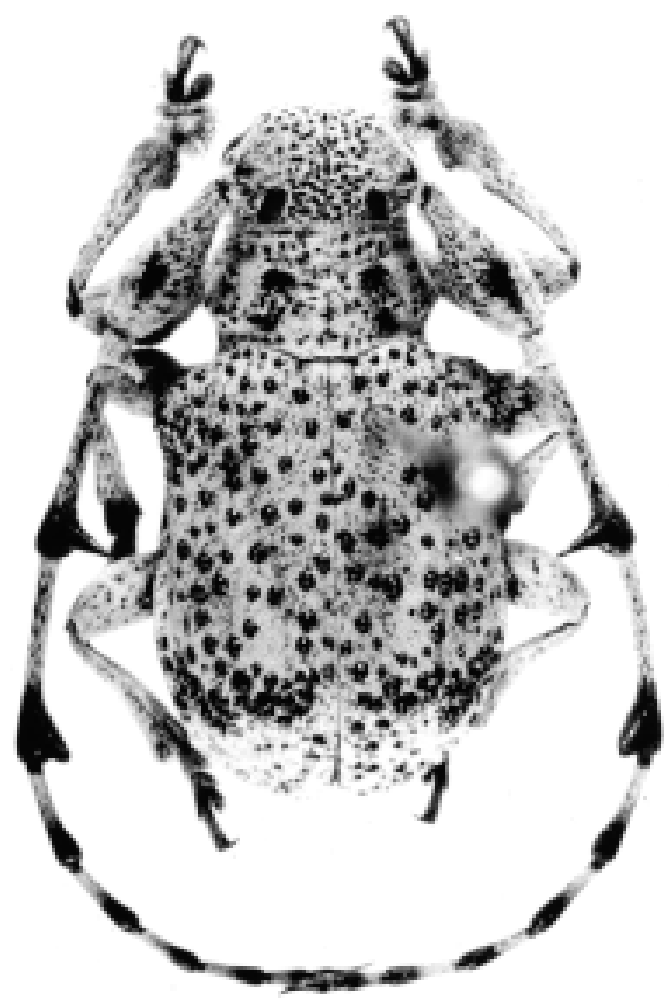

Fig. 1. Demophoo hammatus (Chabrillac, 1857), $\sigma$ (MNRJ), Corcovado, Rio de Janeiro, Brasil, comprimento $9,4 \mathrm{~mm}$.

3. Tegumento predominantemente negro; pernas castanho-escuras; superfície corporal revestida por densa pubescência decumbente branca. Fronte recoberta por grânulos pretos, um pouco convexa, com os lados ligeiramente convergentes para a região inferior e a margem inferior reta; lobos oculares superiores tão distantes entre si quanto, aproximadamente, três vezes a largura de um lobo. Antenas ultrapassam os ápices elitrais a partir do antenômero V; escapo robusto, clavado, um pouco mais curto que os antenômeros III e IV, estes subiguais em comprimento e com espinhos castanhoescuros; antenômeros V-X com o ápice castanho-escuro e gradualmente decrescentes em comprimento; o XI castanho-escuro, mais longo que o precedente e com a forma de aguilhão recurvado. Tubérculo lateral do protórax rombo, pouco proeminente; elevações do pronoto glabras; processo mesosternal desarmado e alargado posteriormente. Élitros com densa granulação negra; elevações centro-basais e no terço apical pouco protuberantes; úmeros salientes e granulados e ápices subarredondados. Profêmures robustos; protíbias com a dilatação apical e a escavação interna acentuadas. Protarsos com franjas laterais negras (fig. 1).

f. Antenas ultrapassam os ápices elitrais a partir do antenômero VIII; profêmures semelhantes aos demais; urosternito $\mathrm{V}$ do tamanho dos três anteriores reunidos e ligeiramente intumescido no ápice. 
Dimensões $(\mathrm{mm})$ respectivamente ${ }^{3} \mathrm{e}$ c. Comprimento total, 7,3-10,5 e 7,7-10,8; protórax, comprimento, 1,3-1,7 e 1,4-2,0, maior largura, 2,7-3,7 e 2,7-4,1; comprimento do élitro, 5,4-7,4 e 5,5-8,1; largura umeral, 3,6-5,2 e 3,6-6,0.

Material examinado. BRASIL, Minas Gerais: Pedra Azul, $\not$, XI.1971; Rio de Janeiro:

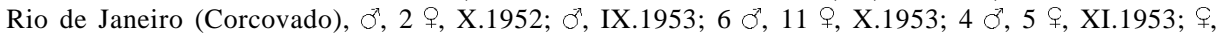

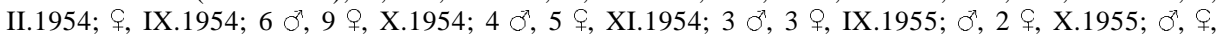
XI.1955; ₹, X.1956; 2 ㅇ, XI.1956; 9 o, 10 f, X.1957, todos D. Zajciw col.; 2 o, 2 ㅇ, X.1957, Alvarenga \& Seabra col.; o, 4 f, XI.1957, D. Zajciw; $\subsetneq$, XI.1957, C.A. Campos Seabra col.; $\sigma^{\circ}, 2$, XI.1957, Alvarenga \& Seabra; ㅇ, XII.1957, C.A. Campos Seabra; , , f, IX.1958, D. Zajciw; 2 , IX.1958, Alvarenga \& Seabra; , X.1958, D. Zajciw; 5 \%, 13 ㅇ, X.1958, Alvarenga \& Seabra; 3 o, 4

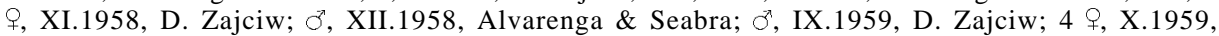
Alvarenga \& Seabra; 8 , , , XI.1959, Alvarenga \& Seabra; , XI.1959; ㅇ, XI.1959, Alvarenga \& Seabra;

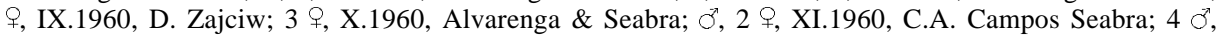
7 , IX.1961, Alvarenga \& Seabra; $\sigma$, X.1961, Alvarenga \& Seabra; $\subsetneq$ (MZSP), XII.1961, M. Alvarenga; o, IX.1966, S.A. Fragoso col.; o, 2 q, X.1966, S.A. Fragoso; ö, X.1966; \&, XI.1966, S.A. Fragoso; 4

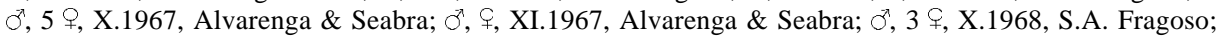
3 , , XI.1968, S.A. Fragoso; ㅇ, XII. 1968, S.A. Fragoso; ö, 2 ㅇ (1 MZSP), X.1969, Alvarenga \& Seabra; $\sigma, 6$, 6 XI.1969, Alvarenga \& Seabra; 3 \&, ㅇ, X.1970, Alvarenga \& Seabra;, , X.1971, C.A. Campos Seabra; q, X.1971, M.A. Monné; 2 ö, 5 f, X.1975, Monné \& Seabra; 2 đ̊, 3 q, X.1976, Monné \& Seabra; ๆ, XII.1976, Monné \& Seabra; ơ, IX.1979, Monné \& Seabra; †, X.1979, Monné \& Seabra; హ, XII.1979, C.A. Campos Seabra; 2 đ̈, X.1980, C.A. Campos Seabra; São Paulo: São Paulo, 2 హ゙, XI.1937, H. Zellibor col. Com exceção daqueles assinalados, todos depositados no MNRJ.

Agradecimentos. Ao Dr. Miguel A. Monné (MNRJ) pelas sugestões e revisão do manuscrito; ao Dr. Ubirajara R. Martins (MZSP) pelo empréstimo de material; a Sérgio Barbosa Gonçalves pela execução das fotografias e a Fundação de Amparo à Pesquisa do Estado de São Paulo (FAPESP, Proc. $\mathrm{n}^{\circ}$ 98/10692-5) pela bolsa de Doutorado concedida.

\section{REFERÊNCIAS BIBLIOGRÁFICAS}

Bates, H. W. 1875. New genera and species of longicorns from South America. Entomologist's mon. Mag., London, 11:273-278.

BlanchaRd, C. E. 1847. Insects de l'Amérique méridionale recueillis par Alcide D'Orbigny, tribu des Longicornes. In: Voyage dans l'Amérique méridionale exécute pendant les annés 1826..., et 1833 par Alcide D'Orbigny. Paris, Bertrand, Strasbourg, Levrault. v.6, n.2, p.206-210, pls.20-22.

Chabrillac, F. 1857. Description de treize espèces de cérambycides. Archiv. ent., Paris, 1:194-200.

Gounelle, E. 1906. Cérambycides nouveaux ou peu connus de la région néotropicale principalement de la sous-region brésilienne. Annls Soc. ent. Fr., Paris, 75:1-20.

Lacordaire, J. T. 1872. Histoire naturelle des insectes. Genera des coléoptères. Paris, Roret. v.9, n.2, p.411-930.

Lane, F. 1938. Notas sôbre lamiideos neotrópicos e descrição de espécies novas (Col., Lamiidae). II. Bolm biol., Nova Série, São Paulo, 3(3-4):107-112.

Monné, M. A. 1994. Catalogue of the Cerambycidae (Coleoptera) of the Western Hemisphere. Part XVII. São Paulo, Sociedade Brasileira de Entomologia. 110 p.

Thomson, J. 1864. Systema cerambycidarum ou exposé de tous les genres compris dans la famille des cérambycides et familles limitrophes. Mem. Soc. Sci. Liège, Liège, 19:1-540.

ZaJcIw, D. 1958. Fauna do Distrito Federal XLVIII. Contribuição para o conhecimento dos longicórneos do Rio de Janeiro (Coleoptera, Cerambycidae). Bolm Mus. nac. Rio de J., Nova Série, Zool., Rio de Janeiro, (189):1-26.

1972. Contribuição para o estudo da fauna dos longicórneos do Parque Nacional do Itatiaia (Coleoptera, Cerambycidae). Brasil Florestal, Rio de Janeiro, 3:40-72.

ZıKÁN, J. F. \& ZIKÁN, W. 1944. A inseto-fauna do Itatiaia e da Mantiqueira. Bolm Min. Agric., Rio de Janeiro, 33(8):1-50.

Recebido em 15.04.2002; aceito em 12.12.2002. 